\title{
DE PRIMAVERA DAS NEVES A VERA PEDROSO: UM PERFIL
}

\section{Denise Bottmann}

I.

Primavera das Neves: que beleza de nome, quase um oximoro perfeito!

É um percurso interessante, cujos elementos principais foram reconstituídos alguns anos atrás pelo cineasta e tradutor gaúcho Jorge Furtado. Até o dado circunstancial que deu origem à sua reconstituição é simpático. Foi assim: em 2010, tendo feito com Liziane Kugland uma nova tradução de Alice no país das maravilhas, de Lewis Carroll, Jorge Furtado resolveu levantar outras traduções da obra e se deparou com uma esquecida ediçãozinha da editora carioca Bruguera, dos anos 60, em nome de uma desconhecidíssima Primavera das Neves. E perguntou-se ele: "Quem foi Primavera das Neves, tradutora de Carroll e de Julio Verne? Seria um pseudônimo? Alguém já ouviu falar dela?" (Furtado, 2010).

Passados alguns anos, Jorge Furtado anuncia: "Encontrei Primavera das Neves", e entre 16 de março e 25 de abril de 2013 publica seus achados e inclui depoimentos de Ivo Barroso e de Eulalie Ligneul (Furtado, 2013).

II.

Eis um breve apanhado biográfico:

Primavera Ácrata Saiz das Neves nasceu em 08 de março de 1933 em Pedrógão Grande, no distrito de Leiria, em Portugal. Era filha da sufragista espanhola Maria Jesusa Saiz y Dias e do anarquista português Roberto Barreto Pedroso Neves (Roberto das Neves), também vegetariano, maçom, grafólogo e esperantista.

Em 1942, a família se muda para o Rio de Janeiro, onde Roberto das Neves cria o Instituto de Pesquisas Grafológicas e a Editora Germinal. Roberto das Neves é tido até hoje como um dos mais expressivos libertários portugueses (Araripe, 1981; Marques, 2013), e sua editora no Brasil, a Germinal, mereceria um estudo à parte.

Primavera estudou no Colégio Franco-Brasileiro (também chamado Lycée Français) do Rio de Janeiro. Em 1944, durante uma campanha de arrecadação de donativos para os soldados da Força Expedicionária Brasileira na Segunda Guerra 
Mundial, sua presença parece ter se destacado. Na matéria "Um exemplo a seguir", comenta o jornalista:

Entre as meninas que representavam as suas colegas, Primavera Saiz das Neves, de onze anos apenas, e da $1^{\mathrm{a}}$. série ginasial, chamou-nos a atenção... terminando a nossa conversa, Primavera respondendo a uma de nossas perguntas, disse-nos: 'O meu presente? Foi dado com o coração'. (Correio da Manhã 1944)

Na quarta série ginasial, vence a Maratona Intelectual do ano (A Manhã, 1947). Aprovada em 1952 no exame para ingresso na Faculdade Nacional de Filosofia da Universidade do Brasil (Correio da Manhã, 1952), em 1955 recebe seu diploma em Línguas Anglo-Germânicas (Correio da Manhã, 1955). Interessante notar que a homenagem de sua turma foi feita à docente Aíla de Oliveira Gomes (ibid.), fina tradutora de, entre outros, Emily Dickinson e Gerard Manley Hopkins. Em 1957, temos a breve notícia de que Primavera das Neves é um dos novos sócios do Museu de Arte Moderna no Rio de Janeiro (Maurício, 1957).

Aos 26 anos, indo passar algum tempo em Portugal, conhece o militar português Manuel Pedroso Marques, com quem se casa pouco tempo depois. Casada, permanece em Portugal com o marido. Em 1960, o casal tem uma filha, Maria Alexandra. Em 1961, o capitão Manuel Pedroso Marques, seu marido, está entre os treze militares que tentam derrubar a ditadura salazarista, na Revolta de Beja. Malogrado o ataque ao quartel de Beja, Manuel Pedroso Marques busca asilo com a família na embaixada brasileira em Lisboa, onde permanece durante um ano e meio. Em 1962, Primavera chega a embarcar num navio com destino ao Brasil, mas a PIDE, a polícia política salazarista, impede-a de partir. ${ }^{1}$ Somente em junho de 1963 consegue Primavera desembarcar no Brasil, trazendo a filha. Sua chegada é noticiada nos jornais A noite, Última Hora e Jornal do Brasil. Em particular, merece destaque a matéria "Dona Primavera chega sem falar em política", com vários dados a partir de uma entrevista direta com ela (Jornal do Brasil, 1963b).

\footnotetext{
1 "Esta senhora" diz o MNI, "acreditando nas promessas da polícia ao embaixador Negrão de Lima, deixara a embaixada e metera-se num navio rumo ao Brasil. Meia hora antes proibiram-lhe a partida, embora estivesse munida do respectivo passaporte, visado pelo consulado brasileiro". (Correio da Manhã, 1962). Ver também A Luta Democrática, “... como há pouco fez [a PIDE] com a ex-asilada dra. Primavera das Neves Pedroso que depois de estar a bordo com sua filhinha, rumo ao Brasil, foi obrigada a abandonar o navio" (LD, 1962).
} 


\section{Hoje no Rio a primeira anti-Salazar \\ Chegari ao Rlo. hoje, as 8h. a bordo do navio Amazo- nas. da Mala Real Inglesa, o procedento de Llsboa, a Sra. Primavera Acrata Siaz das Neves, a primelra des 13 pes- zoos asliadas na Embalxada do Brasil, em Portugal, a con- seguir salvo-conduto para del- xat o pais. \\ Dona Primavera - que so encontrava asilada desde 31 de dezembro de 1960 - participou da Revolta de Beja, contra o Govirno Salszar, c chega- rí acompanhada de uma fi- tha de tres anos.}

A cobertura da imprensa deve ser entendida no contexto da luta antissalazarista (Jornal do Brasil 1963a)

Primavera das Neves à chegada com a filha Maria Alexandra, recebida pelo pai Roberto das Neves (A noite,1963)

III.

Primavera das Neves, antes de partir para Portugal, já se envolvera em atividades editoriais e jornalísticas, trabalhando como secretária na Revista Cinelândia. Sendo seu pai um editor, sendo ela poliglota, nada mais natural do que retomar a área. 
Sua primeira tradução é feita já no ano de sua volta ao Brasil, para a Bruguera: uma adaptação ilustrada de Viagem ao centro da terra, de Júlio Verne, em 1963.

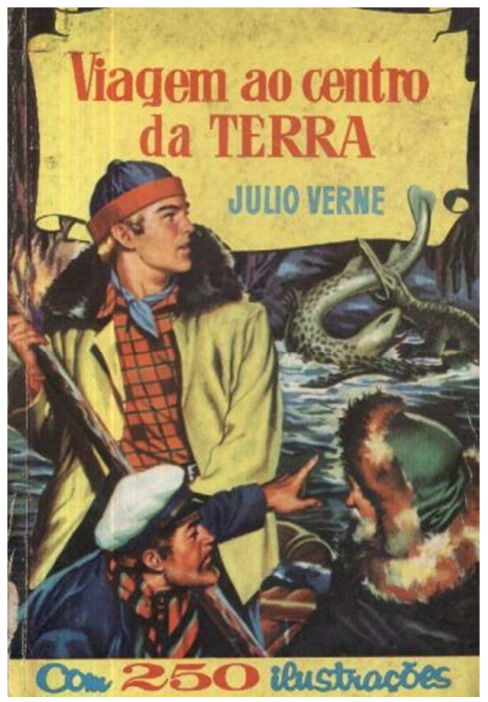

Bruguera, 1963

Nesses primeiros tempos de seu retorno ao Brasil, Primavera traduz algumas obras esporádicas para outras editoras: a Germinal (de seu pai Roberto das Neves), a Lidador e a Fundo de Cultura. Entre essas obras, destaca-se Mistério e solidão, a vida e a obra de Emily Dickinson, de Thomas H. Johnson, em 1965. Nessa alentada obra, Primavera verte nada menos que 220 poemas de Emily Dickinson (é irresistível a tentação de vermos aí alguma inspiração, mesmo que remota e indireta, da mestra que fora homenageada por sua turma durante a colação de grau em 1955, Aíla de Oliveira Gomes, citada mais acima). Com tal empreitada, ela se torna a principal tradutora embora pouco reconhecida e raramente citada - da poetisa americana no Brasil por quase cinquenta anos, vindo sua dickinsoniana a ser superada apenas em data recente. ${ }^{2}$ Para se ter uma ideia dessa proeza de Primavera das Neves, consulte-se o exaustivo levantamento da dickinsoniana brasileira feito pelo professor e tradutor Carlos Daghlian, no portal Emily Dickinson.

Entre 1966 e 1967, Primavera passa a colaborar no projeto da Delta Larousse, a cargo de Antônio Houaiss, como uma dentre os vários tradutores incumbidos de traduzir verbetes para a enciclopédia. Segundo Ivo Barroso, então o encarregado de rever as traduções da seção de tecnologia, por quem passaram verbetes vertidos por ela, foi em

\footnotetext{
${ }^{2}$ Mais especificamente, a partir de 2008, com os trabalhos do poeta e tradutor José Lira publicados em Emily Dickinson: A Branca Voz da Solidão.
} 
tal ocasião que nossa amiga deixou de usar o nome Primavera das Neves, por parecer "meio cafona para as meninas avançadas nossas colaboradoras à época, e adotou Vera [Neves] Pedroso" (Ivo Barroso apud Furtado, 2013). ${ }^{3}$

A partir de 1968, Primavera das Neves volta a se dedicar à tradução de livros, de maneira mais sistemática, concentrando-se em trabalhos para a editora Expressão e Cultura. O editor da Expressão e Cultura era o lusitano radicado no Brasil Fernando de Castro Ferro, aliás também tradutor. A essas alturas, o marido de Primavera, já estando em seu exílio no Brasil, trabalha por dois ou três anos com Fernando Ferro, vindo depois a assumir o cargo de editor após a saída de Ferro. Pelos livros traduzidos por Primavera na Expressão e Cultura de 1968 a 1974, tem-se um perfil de bastante coerência na qualidade das obras traduzidas, sejam historiográficas (Leslie Bethell e o William Styron de Nat Turner) ou literárias (Lawrence Durrell).

Aliás, é nesse período e a Primavera que se deve reconhecer a iniciativa de introduzir a obra de Adolfo Bioy Casares no Brasil. Em 1970, sempre para a Expressão e Cultura, ela traduzira um livro da escritora argentina Beatriz Guido, Antes do incêndio. Algum tempo depois, a autora vem ao Brasil e apresenta uma palestra na Faculdade de Letras da Universidade da Guanabara, onde discorre sobre a importância da obra de Bioy Casares, citando o Diário da Guerra do Porco "como o melhor livro que se escreveu nos últimos anos na Argentina" (Pedroso, 1972). Certamente não terá sido por coincidência que, em 1972, a Expressão e Cultura publica a primeira tradução de Bioy Casares no Brasil, feita por... Vera Neves Pedroso: justamente o Diário da Guerra do Porco. Dois anos depois, em 1974, prosseguindo na divulgação da obra de Bioy Casares entre nós, Primavera traduz La invención de Morel, que é publicada pela Expressão e Cultura com o título de A máquina fantástica.

\footnotetext{
${ }^{3}$ Vale a pena consultar a série "Lembranças de Antônio Houaiss", I-IV, de Ivo Barroso, com uma viva descrição dos trabalhos desenvolvidos pela numerosa equipe em torno da Enciclopédia Delta Larousse, em especial I e II (Barroso 2012).
} 


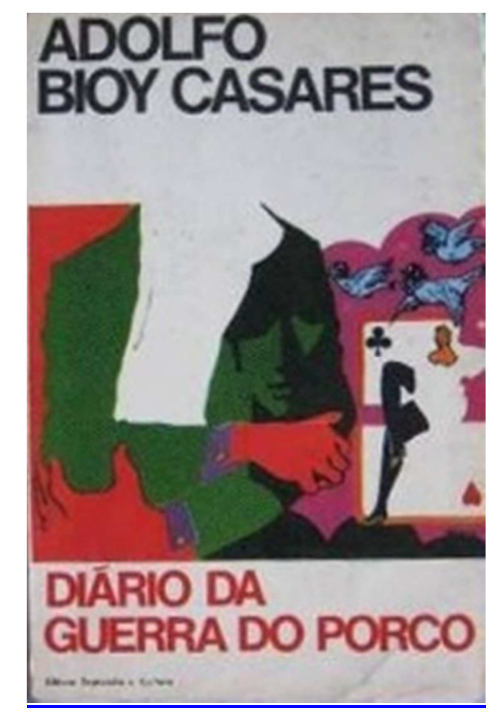

Expressão e Cultura, 1972

Ainda na fase em que seus trabalhos se concentravam na Expressão e Cultura, temos em 1973 um lançamento interessante: Transparências, de Vladimir Nabokov, que ainda não era tão sobejamente conhecido no Brasil. A tradução de Primavera sai pela Cedibra, e aqui cabe esclarecer: logo antes, c.1972, a Editorial Bruguera encerrou suas atividades no Brasil, surgindo a Cedibra, que incorporou parte de seu catálogo e, pelo visto, continuou a recorrer a alguns colaboradores da casa.

Em 1974, com a Revolução dos Cravos, o militar revolucionário marido de Vera / Primavera, "tendo algumas contas a acertar com o regime", decide voltar a Portugal, ao passo que a esposa prefere permanecer com a filha no Brasil, e assim sobrevém a separação do casal.

A partir dessa mesma época, Primavera reduz drasticamente a frequência de suas traduções para a Expressão e Cultura, faz alguns trabalhos esparsos para a Civilização Brasileira e a Nova Fronteira, e dedica-se sobretudo a traduções para a editora Record. Nesta casa, a obras de inegável qualidade somam-se vários best-sellers e títulos de qualidade duvidosa. $\mathrm{O}$ ritmo de produção de Primavera aumenta expressivamente a partir de 1975-76 e assim se mantém até 1979. Sua última tradução foi Guia do neurótico normal, de Allan Fromme, publicada pela Nova Fronteira em 1980. Primavera Ácrata Saiz das Neves Pedroso morre em idade prematura, aos 47 anos de idade, no ano de $1980 .^{4}$

\footnotetext{
${ }^{4}$ O Catálogo de Autoridade de Nomes da Fundação Biblioteca Nacional, porém, dá 1981 como ano de sua morte.
} 
IV.

Para além dos verbetes traduzidos para a Enciclopédia Delta Larousse, consegui localizar 74 [75] obras de tradução de Primavera, distribuídas irregularmente de 1963 a 1980, publicadas pelas seguintes editoras:

- Germinal: 1

- Fundo de Cultura: 1

- Liceu: 1

- Cedibra: 1

- Francisco Alves: 1

- Ediouro: 1

- Lidador: 2

- Civilização Brasileira: 2

- Nova Fronteira: 7

- Bruguera: 14

- Expressão e Cultura: 15 [16, se contarmos Bakakai; vide nota 5]

- Record: 28

A Bruguera foi uma importante editora espanhola de livros populares, histórias infantis, adaptações infanto-juvenis e edições de bolso, sediada em Barcelona, com sucursais em Portugal (com o nome de Editorial Íbis) e vários países da América Latina. No Brasil, a Editorial Bruguera esteve instalada no Rio de Janeiro, de c.1961 a c.1972. Entre suas várias coleções, destacam-se as adaptações infantis e infanto-juvenis nas coleções Heidi e Historias Selección. Nas coleções Ciencia Ficción e Libro Amigo, temos edições integrais de clássicos da literatura universal e de ficção científica.

Informa o poeta e tradutor Leonardo Fróes, editor da Bruguera nos anos 60 e início da década de 70, que as traduções brasileiras das coleções e adaptações infantojuvenis, como Heidi e Histórias, eram feitas a partir do espanhol, nas edições da Bruguera de Barcelona, seguindo suas respectivas adaptações, ilustrações e imagens de capa. $^{5}$ (Fróes, 2015) Entre os catorze títulos traduzidos por Primavera das Neves para a editora, as traduções indiretas, a partir do espanhol, seriam:

\footnotetext{
${ }^{5}$ Para o catálogo original da Colección Histórias Selección Bruguera, veja-se Colección (2013).
} 
- Andersen, Contos de Andersen. Coleção Histórias [1966]

- Carroll, Lewis. Alice no país das maravilhas. Coleção Histórias [1966]

- _ _ _ Alice no país do espelho. Coleção Histórias [c.1966]

- D’Isard, Marcel (pseud. de J.M. Carbonell). Napoleão. Coleção Histórias

- Dooley, Elliot (pseud. de Enrique Martinez Fariñas). A conquista do espaço História da aviação. Coleção Histórias, 12

- Farinacci, Enrico (pseud. de Enrique Martinez Fariñas). Júlio César. Coleção Histórias

- Hodgson, Robert P. A conquista dos polos. Coleção Histórias [1966]

- Stevenson, Robert L. A ilha do tesouro. Coleção Histórias, 8 [1966]

- Verne, Júlio. Viagem ao centro da terra. Coleção Histórias [1963]

- VV.AA. O gato com botas. Bruguera. Coleção Heidi [1966]
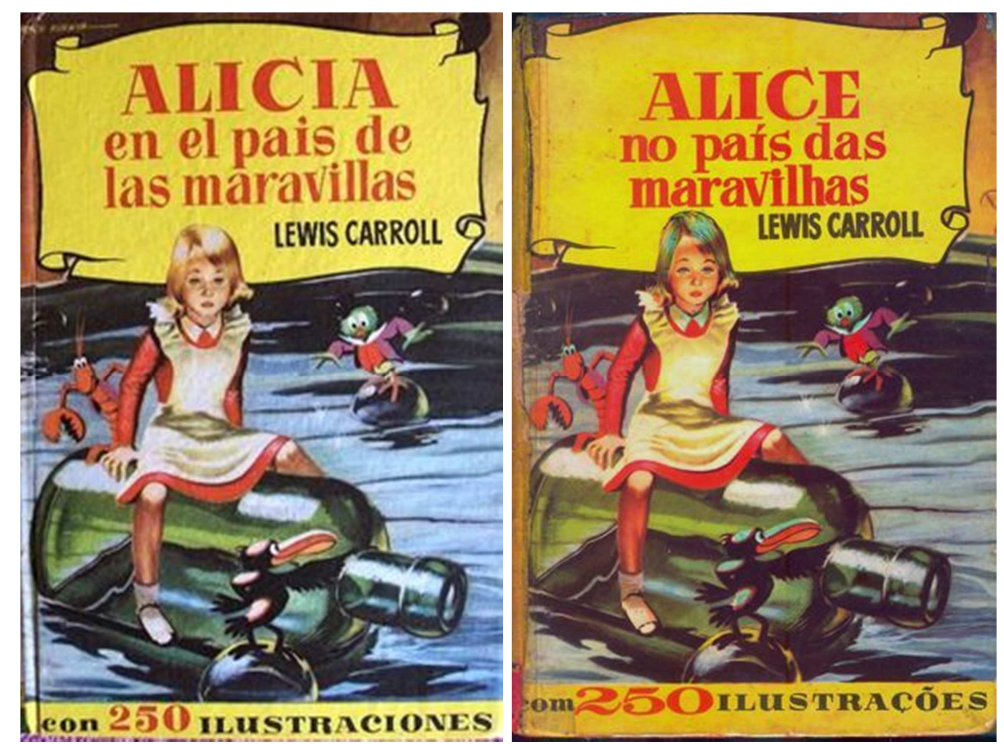

Já as traduções brasileiras das coleções Livro Amigo e Ficção Científica, informa Fróes, sempre foram feitas a partir das línguas originais (idem). ${ }^{6}$ Assim, como traduções diretas teríamos:

- Anderson, Poul. O sol invisível. Coleção Ficção Científica, 2. 1968

- Brontë, Emily. O morro dos ventos uivantes. Coleção Livro Amigo, 44. 1971

\footnotetext{
${ }^{6}$ Para a relação dos títulos publicados na Coleção Livro Amigo no Brasil, ver Editorial Bruguera 2010. O verbete da Wikipédia brasileira, porém, traz informações equivocadas sobre a Bruguera, dando-a como argentina, com base em Hallewell (p. 675, 685). Esse equívoco se reproduz em "Revolução da Brochura", também baseando-se em Hallewell (Oliveira, 2007).
} 
- Flaubert, Gustave. Madame Bovary. Coleção Livro Amigo, 27. 1969

- Uris, Leon. Exodus. Coleção Livro Amigo, 52; Clássicos do Mundo Todo, 49. Bruguera, c. 1972

Detive-me mais demoradamente nos trabalhos de Primavera das Neves para a Bruguera, por se tratar de uma editora especialmente interessante, ainda à espera de um resgate de sua presença no Brasil.

Mas voltemos a nosso tema central. Entre a produção de Primavera, várias de suas traduções alcançaram grandes tiragens. Isso sobretudo pela licença de uso concedida a outras editoras. Por exemplo, a Expressão e Cultura licenciou algumas traduções para editoras portuguesas, em especial a Bertrand. E especialmente a Record licenciou diversos títulos para o Círculo do Livro, a Abril Cultural e a Nova Cultural, publicados em suas coleções para venda domiciliar e em bancas de jornais. Algumas saíram também pelas coleções de bancas da Rio Gráfica e da Record Altaya. Como as tiragens dessas coleções eram altíssimas em comparação às tiragens normais para livrarias, e não raro recebiam várias reedições, pode-se calcular que a distribuição dessas traduções de Primavera das Neves teve enorme alcance entre o público leitor, certamente ultrapassando a casa do milhão.

Cabe notar que ela assinou sua primeira tradução, em 1963, como Primavera das Neves, em Viagem ao centro da Terra. Manteve este nome em outras três traduções da série ilustrada da Bruguera, A ilha do tesouro, Alice no país das maravilhas e Alice no país do espelho. Há uma ocorrência avulsa como Primavera Ácrata das Neves (Macrobiótica Zen), uma como Vera das Neves Pedroso (Mistério e solidão, a vida e a obra de Emily Dickinson) e uma como Vera Pedroso ("Philimor, alma de criança"). Nas demais, comparece como Vera Neves Pedroso. Nas resenhas e matérias de imprensa, aparece algumas vezes como Vera Pedroso, apenas.

\section{V.}

Ao que pude rastrear, sua obra de tradução é a seguinte, por ordem alfabética de autor: $^{7}$

\footnotetext{
${ }^{7}$ Um dos graves problemas em arrolamentos de obras publicadas pela Record é que, até finais dos anos 1970, a editora não costumava dar o ano de edição, fazendo constar apenas o ano de lançamento da obra no original.
} 
1. Andersen, Hans Christian. Contos de Andersen. Coleção Histórias. Bruguera, 1966

2. Anderson, Poul. O sol invisível. Coleção Ficção Científica, 2. Bruguera, 1968

3. Anglade, Christiane, et. al. Por quê? Tempo de Saber, Série A, 1. Liceu, 1973

4. Bach, Richard. O dom de voar. Record, c.1976

5. __ O paraíso é uma questão pessoal. Record. Reed. Círculo do Livro

6. Barnard, Christian. Coração - Mito e realidade. Expressão e Cultura, 1974

7. Battaglia, William, e Tarrant, John, J. O executivo, esse eunuco. Expressão e Cultura, 1975

8. Benet, Laura. Poetas Americanos Famosos. Lidador, 1965

9. Bethell, Leslie. A abolição do tráfico de escravos no. Brasil. Expressão e Cultura/EDUSP, 1976

10. Bocuse, Paul. A cozinha de Paul Bocuse. Trad. com Luzia Machado da Costa. Record, 1976

11. Brontë, Emily. O morro dos ventos uivantes. Coleção Livro Amigo, 44. Bruguera, 1971. Reed. Art, Círculo do Livro

12. Buck, Pearl S. A grande travessia. Record. Reed. Record-Altaya, BestBolso

13. Caldwell, Taylor. A luz e as trevas. Record. Reed. Nova Cultural

14. . O fantasma de Clara. Record. Reed. Clube do Livro

15. Carlander, Ingrid. As americanas. Civilização Brasileira, 1975

16. Carroll, Lewis. Alice no país das maravilhas. Bruguera, 1966. (como Primavera das Neves)

17. Alice no país do espelho. Bruguera, c.1966 (como Primavera das Neves)

18. Casares, Adolfo Bioy. A máquina fantástica. Prefácio de Jorge Luis Borges. Expressão e Cultura, 1974. Reed. Círculo do Livro (Reed. Rocco como A invenção de Morel)

19. _. Dário da Guerra do Porco. Expressão e Cultura, 1972

20. Churchill, R. S.; Churchill, W. S. Seis dias de uma guerra milenar. Expressão e Cultura/Bibliex, 1968

21. Clarke, Arthur C. O fim da infância. Nova Fronteira, 1979. Reed. Círculo do Livro

22. D’Isard, Marcel. Napoleão. Coleção Histórias. Bruguera 
23. Dooley, Elliot. A conquista do espaço - História da aviação. Coleção Histórias, 12. Bruguera

24. Durrell, Lawrence. Tunc. Expressão e Cultura, 1968

25. Farinacci, Enrico. Júlio César. Coleção Histórias. Bruguera

26. Flaubert, Gustave. Madame Bovary. Coleção Livro Amigo, 27. Bruguera, 1969. Reed. Íbis (Portugal)

27. Fox, Emmet. O Sermão da Montanha e o Pai-Nosso. Record. Reed. BestSeller

28. Friedman, Myra. Enterrada Viva - A Biografia de Janis Joplin. Civilização Brasileira, 1975

29. Fromme, Allan. Guia do neurótico normal. Nova Fronteira, 1980

30. Gallico, Paul. Tragédia no mar. Expressão e Cultura, 1972

31. Gifford, Thomas. O vento frio do passado. Record, 1976

32. Gombrovicz, Witold. "Philimor, alma de criança" in Os 100 contos de humor da literatura universal, org. Flávio Moreira da Costa. Ediouro, 1990 (como Vera Pedroso $)^{8}$

33. Guest, Judith. Gente como a gente. Record, s/d. Reed. Círculo do Livro, Abril Cultural

34. Guido, Beatriz. Antes do incêndio. Expressão e Cultura, 1970

35. Guimard, Paul. As coisas da vida. Expressão e Cultura, 1968

36. Hartley, Norman. O processo viking. Record, 1977

37. Heller, Joseph. Gold vale ouro. Nova Fronteira, 1979. Reed. Círculo do Livro

38. Hodgson, Robert P. A conquista dos polos. Coleção Histórias. Bruguera, c.1966

39. Johnson, Thomas H. Mistério e solidão, a vida e a obra de Emily Dickinson. Lidador, 1965 (como Vera das Neves Pedroso)

40. Khomeini, Aiatolá. O Livro Verde dos Princípios Políticos, Filosóficos, Sociais e Religiosos. A partir da tradução do persa para o francês de Jean-Marie Xavière. Record, c.1979

41. Le Carré, John. A vingança de Smiley. Record, c.1979. Reed. Círculo do Livro, Abril Cultural

\footnotetext{
${ }^{8}$ Este caso é interessante. Em 1968, a Expressão e Cultura publicou a coletânea de contos Bakakai, de Gombrowicz. Nos créditos de tradução consta o nome de Álvaro Cabral, outro sério tradutor da casa. Flávio Moreira da Costa, organizador do volume Os 100 melhores contos de humor da literatura universal, relata que estava na editora por ocasião do lançamento do livro, quando veio à baila o erro na atribuição dos créditos, pois em verdade a tradução fora feita por Vera Neves Pedroso. Assim, em Os 100 melhores contos de humor, Flávio Moreira da Costa procurou, em suas palavras, restabelecer a verdade, retificando os créditos de "Philimor" em favor de Vera Pedroso (Costa, 2015).
} 
42. Sempre um colegial. Record, 1978. Reed. Círculo do Livro, Riográfica

43. McDonald, Gregory. Fletch. Record, 1977

44. Michener, James A. Sayonara. Record. Reed. Nova Cultural

45. Nabokov, Vladimir. Transparências. Cedibra, 1973

46. . Somos todos Arlequins. Record, c.1977

47. Natoli, Luigi. Os beatos. Record, 1976 (com Remy Gorga Filho)

48. O’Hara, John. Os Lockwood (Tragédia de uma família americana). Expressão e Cultura, 1973

49. Ohsawa, George. Macrobiótica Zen: Arte da longevidade e do rejuvenescimento. Germinal, 1965 ( $3^{\mathrm{a}}$. ed.) (como Primavera Ácrata das Neves; orelha por Roberto das Neves)

50. Pearson, James. Os gêmeos. Expressão e Cultura, 1974

51. Prebisch, Raul. Dinâmica do desenvolvimento latino-americano. Brasil Fundo de Cultura, 1964

52. Rampa, Mama San Ra'ab. Gatos e homens. Record, 1978

53. Rampa, T. Lobsang (pseud. de Cyril Henry Hoskin). Três vidas. Record, 1978. Reed. Círculo do Livro, Centro do Livro Brasileiro (Portugal)

54. Rey, Henri-François. Neuroforia. Expressão e Cultura, 1968. Reed. Bertrand de Portugal (como $O$ Rachdingue)

55. Rossner, Judith. De bar em bar. Record. Reed. Círculo do Livro, Abril Cultural

56. Serling, Robert J. Café, chá ou crime? Record, 1975

57. Shaw, Irvin. Plantão da noite. Record. Reed. Círculo do Livro, Nova Cultural

58. Simenon, Georges. As férias de Maigret. Nova Fronteira. Reed. L\&PM

59. __. As testemunhas rebeldes. Nova Fronteira. Reed. Círculo do Livro, L\&PM

60. Spielberg, Steven. Contatos imediatos do terceiro grau. Record, 1978

61. Stallone, Sylvester. Cozinha do inferno. Record, 1978. Reed. Círculo do Livro

62. Stevenson, Robert L. A ilha do tesouro. Coleção Histórias, 8. Bruguera, 1966 (como Primavera das Neves)

63. Styron, William. A escolha de Sofia. Record, 1979. Reed. Círculo do Livro, Geração Editorial

64. Styron, William. As confissões de Nat Turner. Expressão e Cultura, 1968. Reed. Bertrand de Portugal, Rocco 
65. Uris, Leon. Exodus. Coleção Livro Amigo, 52, Clássicos do Mundo Todo, 49. Bruguera, c.1972. Reed. Círculo do Livro, Abril, Record, BestBolso

66. Van Slyke, Helen. Entre o amor e a razão. Record, c.1979. Reed. Círculo do Livro

67. Os ricos e os justos. Record, s/d

68. Verne, Júlio. Viagem ao centro da terra. Coleção Histórias. Bruguera, 1963 (como Primavera das Neves). Reed. Abril Cultural

69. Volkoff, Vladimir. A conversão. Nova Fronteira, 1980

70. VV.AA. O gato com botas. Coleção Heidi. Bruguera, c.1966

71. Wallace, Edgar. O homem de Marrocos. Francisco Alves, 1979

72. Watson, Lyall. O macaco onívoro. Expressão e Cultura, 1974

73. Wilden, Theodore. Morrer em outro lugar. Nova Fronteira, 1979

74. Willis, Ted. Olhos sinistros. Record, 1978

VI.

Agora, de passagem, comento rapidamente uma singular ocorrência. Em 2007, a editora paulista Landmark publicou $O$ morro dos ventos uivantes, de Emily Brontë, em edição bilíngue, atribuindo os créditos de tradução a Carolina Caires Coelho. ${ }^{9}$ Em meu blogue Não Gosto de Plágio, apontei que, na verdade, a pretensa tradução não passava de uma cópia levemente adulterada da tradução de Vera Neves Pedroso, que saíra pela Bruguera em 1971 (Bottmann, 2009). O caso foi parar na justiça, sendo que a perícia judicial confirmou a flagrante ocorrência de plágio de tradução. A editora retirou a obra de circulação e a substituiu por outra tradução. Fico contente que se tenha feito essa pequena justiça póstuma a Primavera das Neves / Vera Pedroso.

\section{VII}

À guisa de conclusão, fica aqui um pungente poema seu (Pedroso, 1978):

\section{Planta no escuro}

Planta que nasces do meu eu em mais puro

e vais crescendo sob o sol do escuro,

\footnotetext{
${ }^{9}$ Esta me assevera em correspondência pessoal que foi contratada apenas para fazer a revisão de texto, não tendo qualquer envolvimento ou responsabilidade pelo ocorrido.
} 
dentro de mim:

Alheia estás ao vômito de sangue,

ao olhar moribundo,

ao cheiro de laquê

e à voz do mundo

que se ouve na tevê.

Alheia estás, mas não estás tão alheia,

que não te sintas como numa teia

tolhida de florir, pasto de aranhas.

\section{Referências}

A LUTA Democrática. Visita do general Delgado, líder da Oposição portuguêsa. 4 set. 1962.

A MANHÃ. Encerra-se hoje a "Semana da Economia" - Entrega dos Prêmios aos Vencedores da Maratona Intelectual. 31 out. 1947.

A NOITE. Chegou ao Brasil a exilada portuguesa d. Primavera e filhinha. 12 jun. 1963.

ARARIPE, Flamínio. Entrevista a Roberto das Neves, anarquista individualista, escritor e editor. Planeta, 104, maio 1981.

BARROSO, Ivo. Lembranças de Antônio Houaiss I-IV. 2012. https://gavetadoivo.wordpress.com/?s=houaiss. Acesso em: 20 maio 2015.

BOTTMANN, Denise. Então a landmark pegou gosto pela coisa? 2009. http://naogostodeplagio.blogspot.com.br/2009/01/landmark-pegou-gosto-pelacoisa.html. Acesso em: 20 maio 2015.

COLECCIÓN HISTÓRIAS SELECCIÓN BRUGUERA: Su História y Títulos Publicados. 2013. http://coleccionhistoriasseleccion.blogspot.com.br/2013/08/pagina-enconstruccion.html. Acesso em: 20 maio 2015.

CORREIO da Manhã. Memorial ao Presidente da República. 14 mar. 1952.

CORREIO da Manhã. Representações pró-asilados vão a ministro. 13 set. 1962.

CORREIO da Manhã. Um exemplo a seguir. 15 ago. 1944.

COSTA, Flávio Moreira da. Correspondência pessoal, maio 2015. 
DAGHLIAN, Carlos. Poemas Traduzidos. Emily Dickinson. Portal UNESP. http://www.ibilce.unesp.br/\#!/departamentos/letras-modernas/emilydickinson/poemas-traduzidos-poem-translations/. Acesso em: 20 maio 2015.

EDITORIAL Bruguera. Coleção Livro Amigo. 2010. http://pt.wikipedia.org/wiki/Editorial_Bruguera. Acesso em: 20 maio 2015.

FRÓES, Leonardo. Correspondência pessoal, mai 2015.

FURTADO, Jorge. Quem é Primavera das Neves? 2010. http://www.casacinepoa.com.br/o-blog/jorge-furtado/quem-\%C3\%A9-primaveradas-neves. Acesso em: 20 mai 2015.

. Primavera das Neves. 2013 http://www.casacinepoa.com.br/o-blog/jorgefurtado/encontrei-primavera-das-neves. Acesso em: 20 mai 2015.

HALLEWELL, Laurence. O livro no Brasil - sua história. Trad. Maria da Penha Villalobos, Lólio Lourenço de Oliveira e Geraldo Gérson de Souza. 2a . ed. rev. e ampl. São Paulo: EDUSP, 2005.

JORNAL do Brasil. Dona Primavera chega sem falar em política para não complicar asilo do marido. 12 jun 1963(b).

JORNAL do Brasil. Hoje no Brasil a primeira anti-Salazar. 12 jun. 1963(a).

MARQUES, Manuel Pedroso. Roberto das Neves: nota bio-bibliográfica. 2013. http://memoanarco.blogspot.com.br/2013/03/roberto-das-neves-nota-bio.html Acesso em: 20 maio 2015.

MAURÍCIO, Jayme. Itinerário das Artes Plásticas - Novos Sócios do Museu de Arte Moderna. Correio da Manhã, 8 ago 1957.

OLIVEIRA, Lívio Lima. A revolução da brochura. Intercom. 2007 http://www.intercom.org.br/papers/nacionais/2007/resumos/R0826-1.pdf. Acesso em: 20 maio 2015.

PEDROSO, Vera Neves. Planta no escuro. Correio do Sul, 30 dez. 1978.

Uma revelação argentina no Brasil, Bioy Casares. Jornal do Brasil, 26 ago. 1972.

\section{Agradecimentos}

Rosa Freire d'Aguiar, Jorge Furtado, Manuel Pedroso Marques, Ivo Barroso, Leonardo Fróes, Flávio Moreira da Costa, Francisco Costa. 